Pacific Journal of Mathematics

THE EXTENDABILITY AND UNIQUENESS OF SOLUTIONS OF 


\title{
THE EXTENDABILITY AND UNIQUENESS OF SOLUTIONS OF ORDINARY DIFFERENTIAL EQUATIONS
}

\author{
STEPHEN R. BERNFELD
}

\begin{abstract}
The extendability of solutions of ordinary differential equations is a fundamental and important property since the analysis of stability and boundedness of solutions requires extendability. This paper is concerned with the preservation of the extendability and uniqueness of solutions under perturbations. In particular conditions on the right hand side of $\dot{x}=f(x)+h(t)$ are exhibited which guarantee the extendability of solutions whenever the solutions of the unperturbed equation $\dot{x}=f(x)$ extend.
\end{abstract}

This paper continues the author's previous study [1] and also includes the question of uniqueness of the zero solution of perturbed equations satisfying an Osgood condition [5] (See also [2] for recent results on the uniqueness of perturbed systems.) Examples are provided to demonstrate the strength of our results. The interested reader may look in [4], [5], [6] for other results on extendability.

2. Notation and preliminaries, Let $R^{d}$ denote $d$-dimensional space. We represent solutions of the Cauchy problem $\dot{x}=f(t, x)$, $x\left(t_{0}\right)=x_{0}$ by $x\left(t, t_{0}, x_{0}\right)$. We shall usually be analyzing the equations

$$
\begin{gathered}
\dot{x}=f(x), \\
\dot{x}=f(x)+h(t),
\end{gathered}
$$

where $f: R \rightarrow R^{+}$is continuous and $h: R \rightarrow R$ is Lebesgue measurable, and

$$
\int^{\infty} \frac{d r}{f(r)}=\infty
$$

Condition $(*)$ is equivalent to the extendability of all solutions of (U) ([1]). We investigate the class of functions $h(t)$ which preserve the extendability of solutions and show by example that this class is, in a meaningful sense, "maximal." Again if we substitute the word uniqueness for extendability in each of our theorems, the results hold by noting condition (*) is essentially the Osgood condition at infinity.

3. Results and examples. Before we state our results we will need the following definitions. 
DEFINITION 3.1. Let $S(T)$ be the class of continuous functions $h(t)$, such that $h: R^{+} \rightarrow R$ and there exists $t_{0} \in R^{+}$such that $h\left(t_{0}\right)>$ $T \geqq 0$.

DEFINITION 3.2. Let $\widehat{S}(T)$ be the class of continuous functions $h(t)$ where $h: R^{+} \rightarrow R$ such that $h(t)<T$ almost everywhere, $T \geqq 0$.

DEFINITION 3.3. Let $* S(T)$ be the class of continuous functions $h(t)$, where $h: R^{+} \rightarrow R$ such that there exists $t_{0}$ such that $h\left(t_{0}\right)<$ $-T \leqq 0$.

Definition 3.4. Let $\bar{S}(T)$ be the class of continuous functions $h(t)$, where $h: R^{+} \rightarrow R$ such that $h(t)>-T$ almost everywhere, $T \geqq 0$.

Using these definitions we see that $S(T) \cap * S(B)$ is the set of continuous functions $h(t)$, where $h: R^{+} \rightarrow R$, such that there exists a $t_{0}>0$ and a $t_{1}>0$ such that $h\left(t_{0}\right)>T \geqq 0$ and $h\left(t_{1}\right)<-B \leqq 0$. Similarly, $\hat{S}(T) \cap \bar{S}(B)$ is the set of continuous functions $h(t)$, where $h: R^{+} \rightarrow R$, such that $-R<h(t)<T$ almost everywhere $(T$ and $B$ can both assume $+\infty$ ).

We now state our results leaving the proofs to $\S 4$.

THeOREM 3.1. Assume $f: R \rightarrow R$ such that

$$
\liminf _{x \rightarrow+\infty} f(x) \geqq-T, \quad T \geqq 0
$$

and

$$
\limsup _{x \rightarrow-\infty} f(x) \leqq B, \quad B \geqq 0 .
$$

Then all solutions of

$$
\dot{x}=f(x)+h(t)
$$

exist in the future for one $h(t) \in S(T) \cap * S(B)$ if and only if all solutions of $(\mathrm{P})$ exist in the future for all $h(t) \in S(T) \cap * S(B)$.

REMARK. An immediate consequence of Theorem 3.1 is the following: we assume $f(x)>0$ for all $x>0$ and $f(x)<0$ for all $x<0$, and all solutions of $\dot{x}=f(x)$ exist in the future. The set $S(0) \cap * S(0)$ is the set of all continuous functions $h(t)$ which change sign. Thus, according to Theorem 3.1, if we know there exists a continuous function $h_{1}(t)$ such that $\left|h_{1}(t)\right|$ is very "small" on a very "small" interval and such that all solutions of

$$
\dot{x}=f(x)+h_{1}(t)
$$


exist in the future, then no matter how "large" we allow $|h(t)|$ to be we still have that all solutions of

$$
\dot{x}=f(x)+h(t)
$$

exist in the future. On the other hand, if we suppose there exists a function $g_{1}(t)$ such that $\left|g_{1}(t)\right|$ is very large and such that there exist solutions of

$$
\dot{x}=f(x)+g_{1}(t)
$$

which do not exist in the future, then no matter how "small" $\left|g_{2}(t)\right|$ is made, there exist solutions of

$$
\dot{x}=f(x)+g_{2}(t)
$$

which do not exist in the future.

In [1], we considered the problem of the existence in the future of all solutions of

$$
\dot{x}=f(t, x)+h(t),
$$

where $f: R \times R \rightarrow R$ and $h: R \rightarrow R$, and both $f$ and $h$ were continuous; and we provided sufficient conditions on $f$ such that all solutions of $\left(P^{\prime}\right)$ existed in the future for all continuous $h$. Now we will discuss the reduced problem in which $f: R \rightarrow R$ and provide weaker conditions on $f$ to get similar results.

THEOREM 3.2. If $\lim \inf _{x \rightarrow \infty} f(x)=-T$ and $\lim \sup _{x \rightarrow-\infty} f(x)=B ; T$, $B \geqq 0$, then all solutions of

$$
\dot{x}=f(x)+h(t)
$$

exist in the future if $h(t) \in \hat{S}(T) \cap \bar{S}(B)$.

REMARK. If $f: R^{+} \rightarrow R\left(f: R^{-} \rightarrow R\right)$ then let $B=\infty(T=\infty)$.

We will now construct an example which shows that the set $\hat{S}(T)$ cannot be extended to include those continuous functions $\{h(t)\}$ such that $h(t)=T$ on an arbitrary interval $[a, b]$ and $0 \leqq h(t)<T$ everywhere else.

EXAMPLE 3.1. We define the following function $f: R^{+} \rightarrow R$ : for each integer $n \geqq 1$ such that $n \leqq x \leqq n+1$

$$
\begin{aligned}
& f(n)=-T+1 / n, \\
& f(n+1)=-T+\frac{1}{n+1}, \\
& f(x)=x^{2}, n+\frac{1}{n^{3}} \leqq x \leqq n+1-\frac{1}{(n+1)^{3}}
\end{aligned}
$$


and $f(x)$ is linear on

$$
n \leqq x \leqq n+\frac{1}{n^{3}}
$$

and on

$$
n+1-\frac{1}{(n+1)^{3}} \leqq x \leqq n+1,
$$

and on $[0,1]$ such that $f(0)=0$. Hence we have

$$
\liminf _{x \rightarrow \infty} f(x)=-T,
$$

and all solutions of

$$
\dot{x}=f(x)
$$

exist in the future. We claim that there exist solutions of

$$
\dot{x}=f(x)+h(t)
$$

which do not exist in the future for any $h(t)$ described above. For $t \in[a, b],(\mathrm{P})$ becomes

$$
\dot{x}=f(x)+T,
$$

and it suffices to show that there exist solutions of (3.1) which do not exist on $[a, b]$; that is, if $t_{0}=a$, there exists a point $x_{0}$ and a solution $x\left(\cdot, a, x_{0}\right)$ of (3.1) such that

$$
x\left(t, t_{0}, x_{0}\right) \rightarrow \infty \text { as } t \rightarrow \hat{t} \leqq b .
$$

We shall prove $\int_{x_{0}}^{\infty} d x / f(x)+T$ is finite, which will establish the claim. We have

$$
\begin{aligned}
& \int_{x_{0}}^{\infty} \frac{d x}{f(x)+T} \\
& \quad \leqq \int_{x_{0}}^{\infty} \frac{d x}{x^{2}+T}+\sum_{n=2}^{\infty} \text { area of } R_{n},
\end{aligned}
$$

where $R_{n}$ is the rectangle of height $n$ and base $2 / n^{3}$. Therefore, area of $R_{n}=2 / n^{2}$ and

$$
\begin{aligned}
\sum_{n=2}^{\infty} & \text { area } R_{n} \\
& =\sum_{2}^{\infty} \frac{2}{n^{2}}<\infty .
\end{aligned}
$$


Hence, since

$$
\int_{x_{0}}^{\infty} \frac{d x}{T+x^{2}}<\infty
$$

we have

$$
\int_{x_{0}}^{\infty} \frac{d x}{f(x)+T}<\infty
$$

We can pick $\bar{x}$ so large that

$$
\int_{\bar{x}}^{\infty} \frac{d x}{f(x)+T} \leqq b-a
$$

which implies, for the initial point $(a, \bar{x})$, there exists a solution of (3.1), $x(\cdot, a, \bar{x})$, such that

$$
x(t, a, \bar{x}) \longrightarrow \infty \text { as } t \longrightarrow \hat{t}<b,
$$

thus proving our claim.

REMARK. When $B=T=\infty$, Theorem 3.2 implies that all solutions of

$$
\dot{x}=f(x)+h(t)
$$

exist in the future for all continuous functions $h(t)$.

If we apply Theorems 3.1 and 3.2 to Example 3.1 we find that if we consider

$$
\begin{aligned}
& \dot{x}=f(x), \quad x>0 \\
& \dot{x}=-f(-x), \quad x<0,
\end{aligned}
$$

then the only admissible perturbation term is $h(t) \equiv 0$; that is, no other continuous function can perturb this system and still preserve existence in the future.

4. Proofs. We now state and prove two lemmas needed in the proof of Theorem 3.1.

Lemma 4.1. Assume $\lim _{x \rightarrow \infty} \inf f(x) \geqq-T, T \geqq 0$, where $f: R^{+} \rightarrow R$ is continuous. Then all solutions of

$$
\dot{x}=f(x)+h(t)
$$

exist positively in the future for one $h(t) \in S(T)$ if and only if all solutions of $(\mathrm{P})$ exist positively in the future for all $h(t) \in S(T)$. 
Proof. The sufficiency follows immediately.

Conversely, assume all solutions exist positively in the future for

$$
\dot{x}=f(x)+j(t)
$$

for some $j(t) \in S(T)$. Assume there exists $g(t) \in S(T)$, points $t_{0}, \hat{t}, x_{0}$, and a solution $x\left(\cdot, t_{0}, x_{0}\right)$ of

$$
\dot{x}=f(x)+g(t)
$$

such that $x\left(t, t_{0}, x_{0}\right) \rightarrow+\infty$ as $t \rightarrow \hat{t}$. We define

$$
h(x)=f(x)+T \text {. }
$$

There exists $K_{1}>T$ such that $g(t) \leqq K_{1}$ for $t \in\left[t_{0}, \hat{t}\right]$. Defining

$$
K_{2}=K_{1}-T>0 \text {, }
$$

we have

$$
f(x)+g(t) \leqq h(x)+K_{2}
$$

for $t \in\left[t_{0}, \hat{t}\right]$. Hence we have the existence of a solution $z\left(\cdot, t_{0}, x_{0}\right)$ of

$$
\dot{x}=h(x)+K_{2}
$$

which does not exist on $\left[t_{0}, \hat{t}\right]$. From [1] we have

$$
\begin{aligned}
& \int_{x_{0}}^{\infty} \frac{d x}{h(x)+K_{2}}<\infty \\
& \quad \longrightarrow \int_{x_{0}}^{\infty} \frac{d x}{h(x)+C}<\infty \text { for any } C>0 .
\end{aligned}
$$

Since $j(t) \in S(T)$, we have the existence of a $t^{1}$ such that $j\left(t^{1}\right)>T$. Hence there exists an interval $[a, b]$ with $t^{1} \in[a, b]$, and a constant $K_{3}>0$ such that $j(t)-T \geqq K_{3}$ for all $t \in[a, b]$. Thus, we have

$$
\begin{aligned}
\dot{x} & =f(x)+j(t) \\
& \geqq h(x)+K_{3}, \quad \text { for } \quad t \in[a, b] .
\end{aligned}
$$

Since

$$
\int_{x_{0}}^{\infty} \frac{d x}{h(x)+K_{3}}<\infty
$$

there exists $x^{1}$ such that 


$$
\int_{x^{1}}^{\infty} \frac{d x}{h(x)+K_{3}} \leqq b-a .
$$

Using (4.1) we see that there exists a solution $x\left(\cdot, a, x^{1}\right)$ of

$$
\dot{x}=h(x)+K_{3}
$$

such that

$$
x\left(t, a, x^{1}\right) \longrightarrow \infty \text { as } t \longrightarrow \tilde{t} \leqq b .
$$

Since $f(x)+j(t) \geqq h(x)+K_{3}$ for $t \in[a, b]$, we have the existence of a solution of

$$
\dot{x}=f(x)+j(t)
$$

which does not exist positively in the future, a contradiction.

LEmma 4.2. Assume $f: R^{-} \rightarrow R$ is continuous such that $\lim _{x \rightarrow-\infty}$ sup $f(x) \leqq T, T \geqq 0$. Then all solutions of

$$
\dot{x}=f(x)+h(t)
$$

exist negatively in the future for one $h(t) \in{ }^{*} S(T)$ if and onlf if all solutions exist negatively in the future for all $h(t) \in{ }^{*} S(T)$.

Proof. We shall reduce the hypotheses to an equivalent set of hypotheses satisfying Lemma 4.1. If we let $y=-x$ then the equation $\dot{x}=f(x)$ becomes

$$
\dot{y}=-f(-y), \quad y>0 .
$$

Since

$$
\begin{aligned}
& \limsup _{x \rightarrow-\infty} f(x) \leqq T \\
\longleftrightarrow & \liminf _{x \rightarrow-\infty}-[f(x)] \geqq-T \\
\longleftrightarrow & \liminf _{y \rightarrow+\infty}[-f(-y)] \geqq-T,
\end{aligned}
$$

and

$$
\begin{aligned}
& h(t) \in{ }^{*} S(T) \\
& \longleftrightarrow-h(t) \in S(T) ;
\end{aligned}
$$

we can reduce the hypotheses on $f(x), h(t)$ and on

$$
\dot{x}=f(x)+h(t)
$$

in Lemma 4.2 by considering the change of variables $y=-x$ 
which transforms the above differential equation to

$$
\dot{y}=-f(-y)-h(t)
$$

in which $-f(\cdot)$ and $-h(\cdot)$ satisfy the hypotheses of Lemma 4.1. Hence we have produced an equivalence between Lemmas 4.1 and 4.2 , thus proving the result.

Proof of Theorem 3.1. If $\liminf _{x \rightarrow \infty} f(x) \geqq-T, T \geqq 0$, and if lim $\sup _{x \rightarrow-\infty} f(x) \leqq B, \quad B \geqq 0$, we can apply Lemmas 4.1 and 4.2 respectively to $h(t) \in S(T)$ and $h(t) \in * S(B)$. Since existence in the future is equivalent to positively and negatively existence in the future we arrive at the result of Theorem 3.1 for $h(t) \in S(T) \cap$ * $S(B)$.

Proof of Theorem 3.2. It is sufficient to show that if $\lim \inf _{x \rightarrow \infty} f(x)=-T, T \geqq 0$, then all solutions of

$$
\dot{x}=f(x)+h(t)
$$

exist positively in the future for $h(t) \in \hat{S}(T)$. Once this is shown, we can use the same techniques as were used in the previous theorem to obtain the result.

Since $h(t) \in \hat{S}(T)$, we have $h(t)<T$ almost everywhere on $[0, \infty)$. Hence $h(t)=T$ on a set of measure zero and there exists no $t$ such that $h(t)>T$. We may in fact assume $h(t)<T$ everywhere and then readily verify the result for $h(t) \in \hat{S}(T)$.

We assume the theorem is not true; that is, there exist an initial point $\left(t_{0}, x_{0}\right)$, a point $\hat{t}$, and a solution $x\left(\cdot, t_{0}, x_{0}\right)$ of

$$
\dot{x}=f(x)+h(t)
$$

such that $x\left(t, t_{0}, x_{0}\right) \rightarrow+\infty$ as $t \rightarrow \hat{t}$. When we consider the interval $\left[t_{0}, \hat{t}\right]$ we can find an $\varepsilon_{1}>0$ such that

$$
h(t) \leqq T-\varepsilon_{1} \text { for all } t \in\left[t_{0}, \hat{t}\right] \text {. }
$$

Since $\lim \inf _{x \rightarrow \infty} f(x)=-T$, we have a sequence of points $\left\{x_{n}\right\}$ such that $x_{n} \rightarrow \infty$ and $\lim _{x_{n} \rightarrow \infty} f\left(x_{n}\right)=-T$.

Hence there exists $N$ sufficiently large such that for $n \geqq N$,

$$
f\left(x_{n}\right)<-T+\varepsilon_{1} .
$$

By the continuity of $f(x)$ we have for each $n, N\left(\delta_{n}\right)$, a $\delta_{n}$ neighborhood of $x_{n}$, such that $x \in N\left(\delta_{n}\right) \rightarrow f(x) \leqq-T+\varepsilon_{1}$. Consequently,

$$
f(x)+h(t) \leqq\left(-T+\varepsilon_{1}\right)+\left(T-\varepsilon_{1}\right)=0
$$


for $t \in\left[t_{0}, \hat{t}\right]$ and $x \in N\left(\delta_{n}\right)$, for all $n \geqq N$. There exists $N l>N$ such that $x_{0} \leqq x_{N l}$ and $f(x)+h(t) \leqq 0$ for $x \in N\left(\delta_{N l}\right)$ and $t \in\left[t_{0}, \hat{t}\right]$. Therefore,

$$
x\left(t, t_{0}, x_{0}\right) \leqq x_{N l}
$$

for $t \in\left[t_{0}, \hat{t}\right]$, a contradiction to $x\left(t, t_{0}, x_{0}\right) \rightarrow+\infty$ as $t \rightarrow \hat{t}$.

5. Concluding remarks. We see that many results on perturbed differential equations that utilize integral conditions can be obtained using the techniques in this paper, as well as in [1]. In addition to uniqueness and extendability, one can get results on the boundedness of solutions of differential equations. A somewhat different analysis can also be realized when considering boundary value problems. It is known that the Nagumo condition [6] is extremely important in obtaining bounds for the derivative of a solution of a two point boundary value problem. We observe that by using the results of [1] and this paper, bounds on the derivative of solutions of a perturbed differential equation with two point boundary conditions can be obtained. This may be quite useful in applications and numerical approximations.

\section{REFERENCES}

1. S. Bernfeld, The extendability of solutions of peaturbed scalar differential equations, Pacific J. Math., 42 (1972), 277-288.

2. S. Bernfeld, R. Driver, and V. Lakshmikantham, Uniqueness for ordinary differential equations, Math. Systems Theory, 9 (1976), 359-367.

3. R. Conti, Sulla prolungabilita delle soluzioni di un sistema di equazioni differenziali ordinaire, Boll. Un. Mat. Ital., 11 (1956), 510-514.

4. V. Lakshmikantham and S. Leela, Differential and Integral Inequalities, Vol. I, Academic Press, New York, 1969.

5. T. Yoshizawa, Stability theory by Liapunov's second method, The Mathematical Society of Japan, Tokyo, (1966).

6. S. Bernfeld and V. Lakshmikantham, An Introduction to Nonlinear Boundary Value Problems, Academic Press, New York, 1974.

Received November 4, 1976.

UNIVERSITY OF TEXAS-ARLINGTON

ARLINGTON, TX 76019 



\section{PACIFIC JOURNAL OF MATHEMATICS}

\section{EDITORS}

RICHARD ARENS (Managing Editor)

University of California

Los Angeles, CA 90024

R. A. BEAUMONT

University of Washington

Seattle, WA 98105

C. C. Moore

University of California

Berkeley, CA 94720

\section{J. DugundJI}

Department of Mathematics

University of Southern California

Los Angeles, CA 90007

R. Finn and J. Milgram

Stanford University

Stanford, CA 94305

\section{ASSOCIATE EDITORS}

\section{E. F. BECKENBACH}

B. H. NEUMANN

F. WoLF

K. YOSHIDA

\section{SUPPORTING INSTITUTIONS}

\author{
UNIVERSITY OF BRITISH COLUMBIA \\ CALIFORNIA INSTITUTE OF TECHNOLOGY \\ UNIVERSITY OF CALIFORNIA \\ MONTANA STATE UNIVERSITY \\ UNIVERSITY OF NEVADA \\ NEW MEXICO STATE UNIVERSITY \\ OREGON STATE UNIVERSITY \\ UNIVERSITY OF OREGON \\ OSAKA UNIVERSITY
}

\author{
UNIVERSITY OF SOUTHERN CALIFORNIA \\ STANFORD UNIVERSITY \\ UNIVERSITY OF HAWAII \\ UNIVERSITY OF TOKYO \\ UNIVERSITY OF UTAH \\ WASHINGTON STATE UNIVERSITY \\ UNIVERSITY OF WASHINGTON \\ AMERICAN MATHEMATICAL SOCIETY
}

The Supporting Institutions listed above contribute to the cost of publication of this Journal, but they are not owners or publishers and have no responsibility for its content or policies.

Mathematical papers intended for publication in the Pacific Jaurnal of Mathematics should be in typed form or offset-reproduced, (not dittoed), double spaced with large margins. Please do not use built up fractions in the text of your manuscript. You may however, use them in the displayed equations. Underline Greek letters in red, German in green, and script in blue. The first paragraph or two must be capable of being used separately as a synopsis of the entire paper. Items of the bibliography should not be cited there unless absolutely necessary, in which case they must be identified by author and Journal, rather than by item number. Manuscripts, in triplicate, may be sent to any one of the editors. Please classify according to the scheme of Math. Reviews, Index to Vol. 39. All other communications should be addressed to the managing editor, or Elaine Barth, University of California, Los Angeles, California, 90024.

The Pacific Journal of Mathematics expects the author's institution to pay page charges, and reserves the right to delay publication for nonpayment of charges in case of financial emergency

100 reprints are provided free for each article, only if page charges have been substantially paid. Additional copies may be obtained at cost in multiples of 50 .

The Pacific Journal of Mathematics is issued monthly as of January 1966. Regular subscription rate: $\$ 7200$ a year (6 Vols., 12 issues). Special rate: $\$ 36.00$ a year to individual members of supporting institutions.

Subscriptions, orders for back numbers, and changes of address should be sent to Pacific Journal of Mathematics, 103 Highland Boulevard, Berkeley, California, 94708.

PUBLISHED BY PACIFIC JOURNAL OF MATHEMATICS, A NON-PROFIT CORPORATION

Printed at Kokusai Bunken Insatsusha (International Academic Printing Co., Ltd.). 8-8, 3-chome, Takadanobaba, Shinjuku-ku, Tokyo 160, Japan.

Copyrit (C) 1975 by Pacific Journal of Mathematics Manufactured and first issued in Japan 


\section{Pacific Journal of Mathematics \\ Vol. 69, No. $2 \quad$ June, 1977}

Carol Alf and Thomas Alfonso O'Connor, Unimodality of the Lévy spectral

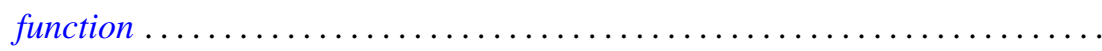

S. J. Bernau and Howard E. Lacey, Bicontractive projections and reordering of

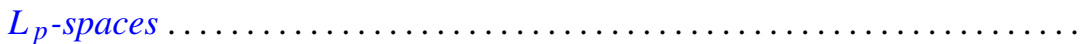

Andrew J. Berner, Products of compact spaces with bi-k and related spaces..... 303

Stephen Richard Bernfeld, The extendability and uniqueness of solutions of ordinary differential equations ...............................

Marilyn Breen, Decompositions for nonclosed planar m-convex sets ..........

Robert F. Brown, Cohomology of homomorphisms of Lie algebras and Lie

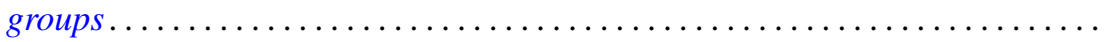

Jack Douglas Bryant and Thomas Francis McCabe, A note on Edelstein's iterative test and spaces of continuous functions ....................

Victor P. Camillo, Modules whose quotients have finite Goldie dimension ....... 333

David Downing and William A. Kirk, A generalization of Caristi's theorem with

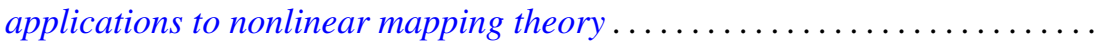

Daniel Reuven Farkas and Robert L. Snider, Noetherian fixed rings ...........

Alessandro Figà-Talamanca, Positive definite functions which vanish at

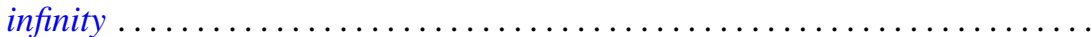

Josip Globevnik, The range of analytic extensions .................. 365

André Goldman, Mesures cylindriques, mesures vectorielles et questions de

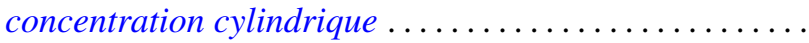

Richard Grassl, Multisectioned partitions of integers..........

Haruo Kitahara and Shinsuke Yorozu, A formula for the normal part of the

Laplace-Beltrami operator on the foliated manifold .... .

Marvin J. Kohn, Summability $R_{r}$ for double series .........

Charles Philip Lanski, Lie ideals and derivations in rings with involution ..

Solomon Leader, A topological characterization of Banach contractions . .

Daniel Francis Xavier O’Reilly, Cobordism classes of fiber bundles . .

James William Pendergrass, The Schur subgroup of the Brauer group . .

Howard Lewis Penn, Inner-outer factorization of functions whose Fourier series

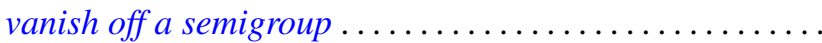

501

William T. Reid, Some results on the Floquet theory for disconjugate definite

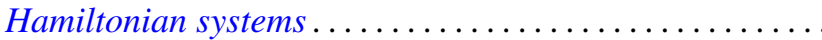

Caroll Vernon Riecke, Complementation in the lattice of convergence

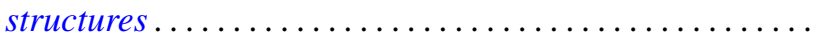

Louis Halle Rowen, Classes of rings torsion-free over their centers ......... 527

Manda Butchi Suryanarayana, A Sobolev space and a Darboux problem ....... 535

Charles Thomas Tucker, II, Riesz homomorphisms and positive linear maps.... 551

William W. Williams, Semigroups with identity on Peano continua ........... 557

Yukinobu Yajima, On spaces which have a closure-preserving cover by finite 